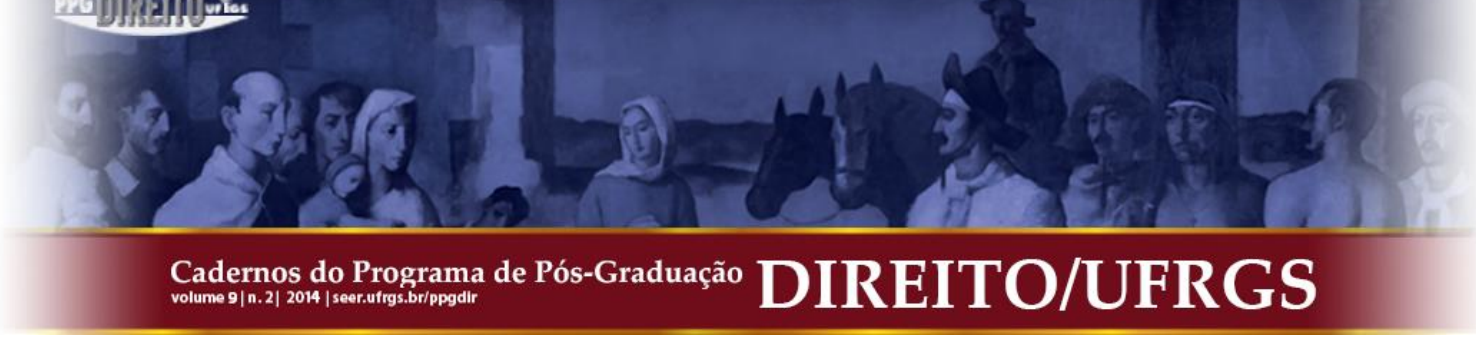

\title{
DA ESPERA EXCESSIVA EM FILA DE BANCO: DA AFRONTA AO PRINCÍPIO CONSTITUCIONAL DA DIGNIDADE DA PESSOA HUMANA
}

\author{
THE EXCESSIVE WAITING IN THE BANK QUEUE: OF THE AFFRONT TO THE \\ CONSTITUTIONAL PRINCIPLE OF HUMAN DIGNITY
}

\author{
Fabiana Cristina da Silveira Alvarenga* \\ Marco Cesar de Carvalho**
}

\begin{abstract}
RESUMO: Este artigo procura demonstrar que a espera injustificada nas filas das agências bancárias fere diretamente o princípio da dignidade da pessoa humana. A espera pelo atendimento em filas revela o desrespeito e falta de atenção ao consumidor. O Código de Defesa do Consumidor dispôs a respeito da proteção e dos direitos básicos do consumidor, à vida, saúde e segurança, educação, informação, contra a publicidade enganosa, à efetiva reparação dos danos advindos da relação de consumo, o direito de acesso à Justiça e órgãos administrativos de proteção e defesa do consumidor, o direito à facilitação da defesa de seus direitos e, por fim, o direito à adequada e eficaz prestação dos serviços públicos em geral. Quando o assunto é o atendimento do cliente bancário, a atuação das instituições financeiras não corresponde às expectativas de seus consumidores quando um cliente fica aguardando um tempo excessivo em fila para ser atendido, além do limite máximo permitido em lei, afrontando o princípio da dignidade da pessoa humana porque é angustiante, gera desgaste físico e mental, além do evidente cansaço e irritação, atingindo a pessoa em sua esfera íntima, ofendendo-lhe a honra e sua condição humana. A atuação das instituições financeiras deve ser repensada tanto na forma de sua estrutura física e instalações como no aspecto de um quadro de funcionários condizente com o número de clientes para atendê-los da melhor forma, com toda a devida consideração e respeito pelos consumidores.
\end{abstract}

PAlAVRAS-CHAVE: Princípio da Dignidade da Pessoa Humana; Direito do Consumidor; Instituições Financeiras; Atendimento Bancário.
ABSTRACT: This article seeks to demonstrate that the unjustified waiting in queues of bank branches directly offends the principle of human dignity. The waiting time in queues shows disrespect and lack of attention to the consumer. The Consumer Defense Code provided for the consumer protection and fundamental rights, such as life, health and safety, education, information, against misleading advertising, effective indemnification for damages derived from the consumption process, the right of access to Justice and administrative organs of consumer protection and defense, the right to a facilitated defense of its rights, and, finally, the right to adequate and effective provision of public services in general. When it comes to the banking customer service, the performance of financial institutions does not match the expectations of its customers when a customer waits for too long in queue to be served, beyond the maximum limit allowed by law, affronting the principle of human dignity because it is distressing, generates physical and mental exhaustion, beyond the obvious fatigue and irritation, impacting the person in its intimate sphere, offending its honor and its human condition. The role of financial institutions should be reconsidered both in its physical structure and installations aspect as in the aspect of a number of staff compatible with the number of customers in order to serve them in the best way, with all due consideration and respect for the consumers.

KEYWORDS: Principle of Human Dignity; Consumer Law Financial Institutions; Banking Services.

SUMÁRIO: Introdução. 1. Nosso ordenamento jurídico. 2. Os princípios constitucionais. 2.1. A juridicidade dos princípios. 2.2. O princípio da dignidade da pessoa humana. 3. O código de defesa do consumidor. 3.1. Os princípios que norteiam o código de defesa do consumidor. 3.2. Dos direitos do consumidor. 3.3. A relação entre o consumidor e fornecedor. 3.4. Da qualidade dos serviços bancários prestados. 4. A atuação das instituições financeiras. Considerações finais. Referências.

\section{INTRODUÇÃO}

\footnotetext{
* Pós-graduanda pela Universidade Paulista.

** Mestrando em Sistema Constitucional de Garantia de Direitos pela Instituição Toledo de Ensino - ITE, campus de Bauru. Pós-graduado em Direito Processual Civil pela FAAP, campus Ribeirão Preto. Especialista em Jurisdição Constitucional pelo Corso di Alta Formazione in Giustizia Costituzionale e Tutela Giurisdizionale dei Diritti III Edizione, ministrado na Università di Pisa, Dipartimento di Giurisprudenza. Professor de Direito do Trabalho, Previdenciário, Processual Civil e Prática Processual Civil na Libertas Faculdades Integradas de São Sebastião do Paraíso.
} 
O presente artigo tem como escopo identificar um problema vivido por muitos, se não pela maioria da população brasileira que utiliza os serviços prestados pelas instituições financeiras. Percebe-se que existe um gravíssimo problema quando o assunto é a atuação dessas instituições com relação ao tempo dos serviços prestados dentro da própria agência, havendo uma demora injustificada no atendimento do cliente.

Nos dias atuais e por conta de muitos compromissos e vida atribulada de todos, vive-se em constante movimento e produção, onde o tempo consumido ao longo do dia numa tarefa deve ser apto a permitir a realização de outras. Mas isto muda caso uma pessoa necessite utilizar-se de quaisquer serviços dentro de uma agência bancária, porque o tempo de espera, em dias comuns poderá ultrapassar em uma hora, isto em centros regionais e com população abaixo de 100 mil habitantes, porque em se tratando dos dias de maior fluxo ( $5^{\circ}$ dia útil e véspera e pós-feriado prolongado), o tempo de espera poderá ser ainda superior.

Em Macapá-AP a Lei n. 1.456/05 estabelece que o tempo de espera em dias normais é de 15 minutos e véspera de feriados de 25 minutos, levando em consideração que a cidade possui em torno de 400 mil habitantes, recentemente o autor de uma ação chegou à instituição bancária às $11 \mathrm{~h} 24 \mathrm{~m}$, e foi atendido às $13 \mathrm{~h} 46 \mathrm{~m}$. Ou seja, o cliente esperou na fila de atendimento por mais de $2 \mathrm{~h}$. (abreviatura errada) Contrariado e bastante ofendido, ele moveu uma indenizatória por danos morais no Juizado Especial Cível e Criminal de Santana, e foi atendido em parte. O banco vai pagar $\mathrm{R} \$ 3.000,00$, mais juros e correção monetária, pelo transtorno, como muito bem fundamentou o juiz Nilton Bianquini em sua decisão ${ }^{1}$, a espera em fila de banco não constitui mero aborrecimento cotidiano, isto porque "é capaz de causar impaciência, angústia, desgaste físico, sensação de descaso e irritação. Sensações estas que, indiscutivelmente, provocam um sofrimento íntimo, além dos dissabores e aborrecimentos próprios do cotidiano".

Nota-se um desestímulo ou falta de incentivo pelas instituições financeiras com relação ao atendimento físico dentro de suas agências. O cliente não consegue organizar seus compromissos num período razoável de tempo, em virtude de ter que aguardar seu atendimento numa fila, o que gera atraso na realização de seus outros compromissos, além do cansaço físico a que é submetido, extrapolando um mero aborrecimento, humilhando e

1 Disponível em: <http://www.tjap.gov.br/portal/publicacoes/noticias/1437-o-consumidor-que-ficou-tempoexcessivo-em-fila-banc\%C3\%A1 ria-deve-ser-reparado-por-espera-no-atendimento.html>. Acesso em: 10 mar. 2014. 
afrontando qualquer pessoa que se sente indignada com tal demora injustificada.

Nosso ordenamento jurídico é responsável pela criação de parâmetros relativos, por exemplo, ao tempo de atendimento, a acomodações dignas e confortáveis para a espera, bem como a regras a serem seguidas, caso contrário é evidente a falha na prestação do serviço bancário prestado, onde a instituição financeira responde objetivamente pelos danos daí advindos de sua ação/omissão. Dentro de uma linha de raciocínio lógico, consumidores e fornecedores deveriam conviver dentro de uma situação harmônica entre si.

\section{NOSSO ORDENAMENTO JURÍDICO}

O artigo $24^{2}$, inciso VIII e $\S \S 1^{\circ}$ a $4^{\circ}$, da Constituição da República Federativa do Brasil (CF/88), estabelece a competência concorrente da União, dos Estados e Distrito Federal e dos Municípios para legislarem a respeito da proteção do consumidor em caso de danos. Por sua vez, o artigo $30^{3}$, inciso I, também da CF/88 estabelece a competência municipal para legislar a respeito de assuntos de interesse local, suplementando as legislações federal e estadual no que couber.

E, em se tratando do exercício de atividades econômicas e financeiras, quem regulamenta a prática do ato ao interesse público é o Código Tributário Nacional (CTN), que em seu artigo $78^{4}$ trata do Poder de Polícia da administração pública, regulando a prática de

\footnotetext{
${ }^{2}$ Art. 24. Compete à União, aos Estados e ao Distrito Federal legislar concorrentemente sobre:

$[\ldots]$

VIII - responsabilidade por dano ao meio ambiente, ao consumidor, a bens e direitos de valor artístico, estético, histórico, turístico e paisagístico.

[...]

$\S 1^{\circ}$ No âmbito da legislação concorrente, a competência da União limitar-se-á a estabelecer normas gerais.

$\S 2^{\circ} \mathrm{A}$ competência da União para legislar sobre normas gerais não exclui a competência suplementar dos Estados.

$\S 3^{\circ}$ Inexistindo lei federal sobre normas gerais, os Estados exercerão a competência legislativa plena, para atender a suas peculiaridades.

$\S 4^{\circ}$ A superveniência de lei federal sobre normas gerais suspende a eficácia da lei estadual, no que lhe for contrário.

${ }^{3}$ Art. 30. Compete aos Municípios:

I - legislar sobre assuntos de interesse local;

II - suplementar a legislação federal e a estadual no que couber;

4 Art. 78. Considera-se poder de polícia atividade da administração pública que, limitando ou disciplinando direito, interesse ou liberdade, regula a prática de ato ou abstenção de fato, em razão de interesse público concernente à segurança, à higiene, à ordem, aos costumes, à disciplina da produção e do mercado, ao exercício de atividades econômicas dependentes de concessão ou autorização do Poder Público, à tranqüilidade pública ou ao respeito à propriedade e aos direitos individuais ou coletivos.
} 
um ato.

De acordo com o texto do CDC, este sendo uma norma geral de consumo, acompanhada suplementarmente pela legislação estadual e pela municipal, com vistas ao interesse local, e, em consonância com as normas constitucionais e mais especificamente com o princípio da dignidade da pessoa humana, há uma suficiente previsão normativa para a proteção do consumidor de qualquer prática abusiva por parte das instituições financeiras, mais ainda na chamada espera injustificada em fila de bancos.

Até porque as instituições financeiras estão sujeitas à aplicabilidade da Lei n. 8.078, de 11 de setembro de 1990, quando entrou em vigor o Código de Defesa do Consumidor (CDC), dispondo a respeito da proteção do consumidor, e dando outras providências, por força tanto do seu próprio texto, como do julgamento da Ação Direta de Inconstitucionalidade (ADI) $2591^{5}$, em 07/06/2006, pelo Supremo Tribunal Federal (STF) em 2006, e, posteriormente, da edição Súmula n. $297^{6}$ pelo Superior Tribunal de Justiça (STJ), ratificando a sujeição dessas instituições ao CDC.

\section{OS PRINCÍPIOS CONSTITUCIONAIS}

\subsection{A juridicidade dos princípios}

Segundo Silva (2009, p. 18), princípios constitucionais são ordenações que se irradiam e imantam os sistemas de normas. Tais princípios podem estar possivelmente incorporados, por serem à base das normas jurídicas, o que os transformaria em normas-princípios constituindo, dessa forma, os preceitos básicos da organização constitucional. Dentre os princípios constitucionais, destacam-se os princípios da dignidade humana, da legalidade, da igualdade, da isonomia de tratamento, da liberdade, do contraditório, da ampla defesa, e da proporcionalidade da lei.

Parágrafo único. Considera-se regular o exercício do poder de polícia quando desempenhado pelo órgão competente nos limites da lei aplicável, com observância do processo legal e, tratando-se de atividade que a lei tenha como discricionária, sem abuso ou desvio de poder.

5 Disponível em: <http://www.stf.jus.br/portal/processo/verProcessoAndamento.asp?incidente=1990517>. Acesso em: 08 mar. 2014.

${ }^{6}$ Súmula no 297 STJ - 12/05/2004 - DJ 09.09.2004 - Código de Defesa do Consumidor - Instituições Financeiras - Aplicação

O Código de Defesa do Consumidor é aplicável às instituições financeiras. 
Ferdinand Lassalle proferiu sua conferência a respeito da essência da Constituição (Uber das Verfassungswesen) numa associação liberal-progressista de Berlin. Segundo sua tese fundamental, a Constituição jurídica não passaria de um pedaço de papel (ein Stuck Papier), porém, percebemos que a Constituição é muito mais profunda que este conceito, ela está vinculada à realidade histórica concreta do seu tempo bem como seus princípios que são voltados para adaptar-se ao Direito que é vivo e a uma sociedade que não é estática. Tanto que em caso de conflito, a Constituição não será considerada a parte mais fraca, sua autonomia está ligada diretamente aos pressupostos realizáveis (realizierbare Voraussetzungen), que mesmo em qualquer caso de confronto, permitem assegurar a sua força normativa. O Direito Constitucional não contradiz a natureza da Constituição. Ele deve explicitar as condições sob as quais as normas constitucionais podem adquirir a maior eficácia possível, auxiliando no desenvolvimento da dogmática e da interpretação constitucional, como nos ensina Hesse (1991, p. 27).

Dessa forma, compete ao Direito Constitucional realçar e preservar a vontade pela Constituição (Wille zur Verfassung), que constitui a maior garantia de sua força normativa, impedindo o surgimento de ilusões relativas a questões fundamentais para a vida do Estado. $\mathrm{O}$ reconhecimento da autenticidade dos princípios dentro da Constituição e das normas jurídicas, num primeiro momento causou entendimento negativo, pois os mesmos eram vistos com uma suposta natureza transcendente, em razão de seu conteúdo e vagueza bem como meras exortações de preceitos de ordem moral ou política, mas nunca reconhecidos como verdadeiros comandos de direito, conforme nos ensina Rothenburg (2003, p. 13).

No sentido do reconhecimento de juridicidade aos princípios, Mello (1981, p. 230) já os conceituava como:

\footnotetext{
Mandamento nuclear de um sistema, verdadeiro alicerce dele, disposição fundamental que se irradia sobre diferentes normas compondo-lhes o espírito e servindo de critério para sua exata compreensão e inteligência, exatamente por definir a lógica e a racionalidade do sistema normativo, no que lhe confere a tônica e lhe dá sentido harmônico.
}

Para o renomado jurista Reale (1991, p. 300): “princípios são certos enunciados lógicos admitidos como condição ou base de validade das demais asserções que compõem dado campo do saber.". Enfim, todos funcionando como um mandamento fundamental, uma base 
de nosso Estado democrático de direito, ao qual o ordenamento jurídico deva conformar-se em respeito ao princípio da integridade e coerência no próprio direito.

\title{
2.2 O princípio da dignidade da pessoa humana
}

Barroso (2013, p. 61) ensina que:

\begin{abstract}
A dignidade humana tem seu berço secular na filosofia, onde pensadores inovadores como Cícero, Pico della Mirandola e Immanuel Kant construíram ideias como antropocentrismo (uma visão de mundo que reserva ao seu humano um lugar e um papel centrais no universo), o valor intrínseco de cada pessoa e a capacidade individual de ter acesso à razão, de fazer escolhas morais e determinar seu próprio destino.
\end{abstract}

Referido autor ainda explica que a dignidade humana tem suas raízes na ética, na filosofia moral e num primeiro momento, o seu valor está diretamente ligado à moralidade, ao bem, à conduta correta e à vida boa. A proteção e promoção da dignidade humana foram consideradas tarefas exclusivas dos poderes políticos do Estado, ou seja, dos poderes Executivo e Legislativo (BARROSO, 2013, pp. 61-62).

Num novo ambiente pós-positivista, no qual a Constituição e os princípios constitucionais, expressos ou implícitos, desempenham uma função central, os juízes e as Cortes necessitam recorrer à moralidade política com a finalidade de aplicar os princípios corretamente, favorecendo assim, a ascensão da dignidade humana. E nesse mesmo sentido, Barroso (2013, p.63) deixa claro que "a dignidade humana é um conceito multifacetado, que está presente na religião, na filosofia, na política e no direito.”. Existindo um razoável consenso de que ela constitui um valor fundamental subjacente às democracias constitucionais de modo geral, mesmo quando não expressamente prevista nas suas constituições.

A $\mathrm{CF} / 88$, em seu artigo $1^{\circ}$, dispõe a respeito da dignidade humana em um regime democrático, republicano do tipo federalista, e enumera os fundamentos do Estado Democrático de Direito brasileiro, baseados na soberania, na cidadania, na própria dignidade da pessoa humana, nos valores sociais do trabalho e da livre iniciativa e no pluralismo político.

Com efeito, a própria Declaração Universal dos Direitos do Homem prevê (artigo 1) que "todos os seres humanos nascem livres e iguais em dignidade e direito". E neste sentido, 
Araújo e Nunes Júnior (2012, p. 133), citando a lição do Padre Laércio Dias de Moura, para quem a noção de dignidade humana está atrelada à concepção de que:

\begin{abstract}
Cada ser humano tem, pois, um lugar na sociedade humana. Um lugar que lhe é garantido pelo direito, que é a força organizadora da sociedade. Como sujeito de direitos ele não pode ser excluído da sociedade e como sujeito de obrigações ele não pode prescindir de sua pertinência à sociedade, na qual é chamado a exercer um papel positivo.
\end{abstract}

$\mathrm{O}$ respeito à dignidade humana constitui princípio fundamental e dessa forma ele independe, para a produção de efeitos jurídicos, de inclusão expressa em texto normativo. Entende-se que o Direito não se faz resumir em texto legal, muito menos é caracterizado como um produto exclusivo de ação estatal. Até porque, e nos valendo das palavras do lusitano Ascensão (2005, p. 52): “O Direito é uma ordem da sociedade, e não uma secreção do Estado.”. O conceito de dignidade humana é complexo. Em síntese refere-se ao fato de que a todos os homens deva haver respeito mútuo e consideração recíproca, já que todos igualmente têm a mesma dignidade.

A cerca da proteção dessa dignidade humana, assim entendida como um direito fundamental para a liberdade, a justiça e a paz mundial, assegurado e garantido na $\mathrm{CF} / 88$, mas, também protegido por um direito supranacional ou por decorrência de um Direito comunitário, decorrente dos pactos e tratados estabelecidos pelos países, como a Declaração Universal dos Direitos Humanos (art. $\mathrm{I}^{7}$ ), de 10 de dezembro de $1948^{8}$, da qual o Brasil é signatário deste então, e a Convenção Americana de Direitos Humanos (Pacto São José da Costa Rica), de 22 de novembro de $1969^{9}$, quando os Estados americanos reafirmaram no continente um regime de liberdade pessoal e de justiça social, onde toda pessoa tem direito ao respeito da sua honra e ao reconhecimento de sua dignidade, não podendo ser objeto de ingerências arbitrárias ou abusivas em sua vida privada (art. $11^{10}$ ). E, de acordo Andrade

\footnotetext{
7 Artigo 1. Todos os seres humanos nascem livres e iguais em dignidade e direitos. São dotados de razão e consciência e devem agir em relação uns aos outros com espírito de fraternidade.

${ }^{8}$ Adotada e proclamada pela resolução 217 A (III) da Assembleia Geral das Nações Unidas em 10 de dezembro de 1948. Disponível em: 〈http://unesdoc.unesco.org/images/0013/001394/139423por.pdf〉. Acesso em: 29 jan. 2014.

9 Adotada e aberta à assinatura na Conferência Especializada Interamericana sobre Direitos Humanos, em San José de Costa Rica, em 22/11/1969 - ratificada pelo Brasil com o depósito da carta de adesão à convenção em 25/09/1992, promulgada pelo Decreto n. 678, de 9/11/1992. Disponível em: <http://www.pge.sp.gov.br/centrodeestudos/bibliotecavirtual/instrumentos/sanjose.htm>.Acesso em 29 jan. 2014.

${ }^{10}$ Artigo 11 - Proteção da honra e da dignidade
} 
(2008 p. 1-2):

\begin{abstract}
No centro do direito encontra-se o ser humano. O fundamento e o fim de todo o direito é o homem, em qualquer de suas representações: homo sapiens ou, mesmo, homo sêmens; homo Faber ou homo ludens; homo socialis, politicus, œconomicus, tecnologicus, mediaticus. Vale dizer que todo o direito é feito pelo homem e para o homem, que constitui o valor mais alto de todo o ordenamento jurídico. Sujeito primário e indefectível do direito, ele é o destinatário final tanto da mais prosaica quanto da mais elevada norma jurídica. Constitui lugar comum a afirmação de que o interesse público ou social deve prevalecer sobre o individual. Mas isso é apenas pensar no homem de forma coletiva. Quando se prioriza um interesse público ou social em detrimento de um interesse individual, supõe-se estar a tutelar, ainda que de forma indireta, o interesse de um número maior de pessoas, ainda que não individualizadas. Assim, seja por que ângulo for o ser humano está no centro de toda e qualquer reflexão jus-filosófica. Por essa razão, todos os princípios constitucionais encontram sua razão e origem no homem, fundamento de todo o dever-ser. E, justamente por ser fundamento, o homem não constitui, em si, um princípio, pois o "fundamento não é um princípio, mas a justificação radical dos próprios princípios.".

A humana condição não fundamenta e justifica o que é, mas o que deve ser, tanto no campo da moral como no do direito. No plano jurídico, como em tudo mais, "o homem é a medida de todas as coisas". A finalidade última do direito é a realização dos valores do ser humano. Pode-se, pois, dizer que o direito mais se aproxima de sua finalidade quanto mais considere o homem, em todas as suas dimensões, realizando os valores que lhe são mais caros.
\end{abstract}

Também neste sentido, Canotilho (2003, p. 1.090) define os princípios jurídicos fundamentais como aqueles: "historicamente objetivados e progressivamente introduzidos na consciência jurídica e que encontram uma recepção expressa ou implícita no texto constitucional.".

Alguns autores entendem que a isonomia é a principal garantia constitucional, e explicam a sua importância, contudo, diante do atual texto constitucional, Nunes (2009, pp. 24-25) entende que "o principal direito constitucionalmente garantido é o da dignidade da pessoa humana e que a dignidade é o primeiro arcabouço da guarita dos direitos individuais e o primeiro fundamento de todo o sistema constitucional.".

Dessa forma o princípio da dignidade da pessoa humana é um valor preenchido a priori, ou seja, todo ser humano tem dignidade só pelo fato já de ser pessoa. Existe uma dificuldade de fixação semântica do sentido de dignidade, não implicando que a mesma possa ser violada. Ainda que não seja definida, é visível quando ocorre sua violação, finaliza Nunes (idem, pp.

1. Toda pessoa tem direito ao respeito da sua honra e ao reconhecimento de sua dignidade.

2. Ninguém pode ser objeto de ingerências arbitrárias ou abusivas em sua vida privada, em sua família, em seu domicílio ou em sua correspondência, nem de ofensas ilegais à sua honra ou reputação. 
25-26).

A introdução do princípio da dignidade humana no texto constitucional é importante para a sua efetiva proteção e o seu amplo desenvolvimento pelos órgãos públicos em geral e, em especial, pelos órgãos de aplicação do Direito. Como observa Sarlet (2001, p. 71): "a dignidade evidentemente não existe apenas onde é reconhecida pelo Direito e na medida em que este a reconhece, já que constitui dado prévio, não esquecendo, todavia, que o Direito poderá exercer papel crucial na sua proteção e promoção.”.

Por isso, é favorável a consagração do princípio da dignidade da pessoa humana no artigo $1^{\text {o11 }}$, III, da $\mathrm{CF} / 88$, como um dos fundamentos do Estado democrático de direito e de nossa própria República, significativamente mesmo, diante da adoção de tal princípio, como símbolo do compromisso assumido pelo Estado brasileiro com os valores mais caros ao homem. E a expressão dignidade surge, ainda, em outros dispositivos constitucionais, como no artigo $226, \S 7^{\circ}$, estabelecendo que o planejamento familiar seja fundado nos princípios da dignidade da pessoa humana e da paternidade responsável; no artigo 227 , caput, instituindo que é dever da família, da sociedade e do Estado assegurar à criança e ao adolescente, com absoluta prioridade, o direito à "dignidade"; no artigo 230, caput, competindo à família, à sociedade e ao Estado o dever de amparar as pessoas idosas, "defendendo sua dignidade".

O princípio da dignidade está contido, ainda que sob roupagem diversa, em outros dispositivos constitucionais, como no artigo $3^{\circ}$, inciso I, que estabelece, dentre os objetivos fundamentais da República Brasileira, a construção de uma "sociedade livre, justa e solidária" e a liberdade, a justiça e a solidariedade são valores que estão vinculados, indissociavelmente, da dignidade humana, porque constituem condições para a sua efetivação. O mesmo dispositivo constitucional indica, como outro objetivo fundamental, "promover o bem de todos, sem preconceitos de origem, raça, sexo, cor, idade e quaisquer outras formas de discriminação" (inciso IV). Consagra-se, aqui, princípio ético já mencionado, qual seja o da igual consideração de interesses. Todos são merecedores de igual consideração por parte do Estado e de seus semelhantes.

A dignidade não é algo a se buscar, pois a mesma está intrínseca na própria condição

\footnotetext{
${ }^{11}$ DOS PRINCÍPIOS FUNDAMENTAIS

Art. $1^{\circ}$ A República Federativa do Brasil, formada pela união indissolúvel dos Estados e Municípios e do Distrito Federal, constitui-se em Estado Democrático de Direito e tem como fundamentos:

$[\ldots[$

III - a dignidade da pessoa humana;
} 
humana, já faz parte de cada um de nós. Não se faz necessário, invocar o princípio da dignidade, que o mesmo venha acompanhado de um direito fundamental específico violado por alguma norma infraconstitucional (SARLET, 2001). Neste caso ele tem duas funções: a primeira defensiva e uma segunda prestacional, ou seja, encerra normas que outorgam direitos subjetivos de cunho negativo (não violação da dignidade) e a outra, o princípio impõe condutas positivas no sentido de proteger e promover a dignidade.

Dentro deste estudo, o que se vê e se demonstrará adiante, é quão grande é o descaso das instituições financeiras ao prestarem serviços aos consumidores, afrontando a dignidade humana de seus próprios clientes.

\section{O CÓDIGO DE DEFESA DO CONSUMIDOR}

A Lei n. 8.078, de 11 de setembro de 1990 (DOU 12/9/1990, ret. DOU 10/1/2007) instituiu o Código de Defesa do Consumidor, visando a proteção e defesa do consumidor em juízo ou fora dele.

O Código de Defesa do Consumidor (CDC) foi instituído pelo artigo $5^{\circ}$ da $\mathrm{CF} / 88$, que dispõe a respeito de direitos e garantias fundamentais, mais precisamente em seu inciso XXXII $^{12}$ que estabeleceu a promoção da a defesa do consumidor pelo Estado. Tal sua importância, que o art. 48 do Ato das Disposições Constitucionais Transitórias estabeleceu que o Congresso Nacional, dentro de cento e vinte dias da promulgação da Constituição, elaboraria o CDC.

Anteriormente a esse dispositivo, a relação de consumo estava inserida dentro do Código Comercial, isso por volta da metade do século XIX. Porém, existiam muitas lacunas e o consumidor, tido sempre como a parte mais fraca desta relação, não estava protegido de forma coerente e adequada, conforme sua necessidade. Dessa forma, com uma ascensão consumista e o dinamismo da sociedade de uma forma geral, viu-se necessária a criação de uma lei que tratasse desse tema com exclusividade, garantindo de forma disciplinar, a proteção na relação entre consumidor e fornecedor.

\footnotetext{
${ }^{12}$ Art. $5^{\circ}$ Todos são iguais perante a lei, sem distinção de qualquer natureza, garantindo-se aos brasileiros e aos estrangeiros residentes no País a inviolabilidade do direito à vida, à liberdade, à igualdade, à segurança e à propriedade, nos termos seguintes: $[\ldots]$ XXXII - o Estado promoverá, na forma da lei, a defesa do consumidor;
} 
Diante dessa necessidade, o Ministério da Justiça criou uma comissão de juristas, com notório saber jurídico e conduta ilibada, para a criação do tão esperado CDC. Tal comissão era presidida pela professora Ada Pellegrini Grinover e integrada por Antônio Herman de Vasconcellos e Benjamim, Daniel Roberto Fink, José Geraldo Brito Filomeno, Kazuo Watanabe, Nelson Nery Júnior e Zelmo Denari. No dia 11 de setembro de 1990, entrou em vigor a Lei n. 8.078/90, estabelecendo o Código de Defesa do Consumidor (CDC), que dispôs a respeito da proteção do consumidor e deu outras providências, dentre elas, a obrigatoriedade do cumprimento da referida lei, caso contrário o fornecedor poderia até mesmo ser preso ou pagar uma prestação pecuniária (multa no valor mínimo de $\mathrm{R} \$ 12$ mil reais).

“A proteção do consumidor é um desafio da nossa era e representa, no mundo todo, um dos temas mais atuais do Direito". Se antes fornecedor e consumidor encontravam-se em uma relação equilibrada, agora é o fornecedor que assume a posição de força na relação de consumo e o Direito não pode ficar alheio a tal fenômeno. Por consequência dessa vulnerabilidade do consumidor por diversas causas, não pode o Direito proteger a parte mais fraca da relação de consumo somente em relação a algumas facetas do mercado, ou seja, não se busca uma tutela manca do consumidor, o objetivo é buscar uma proteção integral, sistemática e dinâmica, nos explica Ada Pellegrini Grinover [et al.] (CÓDIGO BRASILEIRO DE DEFESA DO CONSUMIDOR, 2007, pp. 6-7).

Já Bittar Filho (2007, p. 344) nos ensina que por força do CDC, varreram-se das relações de consumo a má-fé, a malícia e o abuso, que passam a ser substituídos pela lisura, pela boa-fé e pela transparência.

Por conta dessas normas e outras também estabelecidas dentro do CDC, a promulgação dessa lei não foi aceita de forma pacífica por parte de seus destinatários, especialmente as instituições financeiras brasileiras, num exemplo claro deste descontentamento. Essas instituições não concordavam com seu enquadramento pela referida lei no conceito de fornecedoras e prestadoras de serviços bancários. Durante algum tempo essas instituições debatiam-se em juízo, alegando que não estavam enquadradas ao artigo $3^{\circ}$ do CDC, e que o cliente não poderia invocar a proteção do Código consumerista quando o litígio versasse a respeito de operações financeiras, como nos ensina Collossal (2007, p. 81).

Tanto que a Confederação Nacional das Instituições Financeiras (CONSIF) ajuizou uma 
ADI de número 2591, junto ao Supremo Tribunal Federal (STF), em 26/12/2001, questionando a inserção e a inconstitucionalidade do artigo $3^{\circ 13}, \S 2^{\circ}$ do CDC, referindo-se aos serviços de natureza bancária, financeira, de crédito e securitária prestados por estas instituições financeiras.

Passadas as primeiras divergências, partindo da premissa de que as instituições financeiras prestam serviços (administram depósitos, efetuam cobrança, aplicam recursos de clientes, prestam atendimento etc.) e vendem produtos (seguros, ações, previdência privada), enquadram-se inafastavelmente das regras do Código de Defesa do Consumidor (COLLOSSAL, 2007, p. 81).

Dessa forma, o Pleno do STF, por maioria, julgou improcedente a $\mathrm{ADI}^{14}$, quando saiu vencido parcialmente o Ministro Carlos Velloso (Relator), e, logo após, o Superior Tribunal de Justiça (STJ), com base em seus julgados precedentes ${ }^{15}$, uniformizou sua jurisprudência, editando a já citada Súmula n. 297, enquadrando de vez as instituições financeiras na aplicabilidade do CDC.

Mas o que importa para o presente artigo é que, de fato e de direito, há uma relação de consumo entre as instituições financeiras e seus clientes, até porque o conceito adotado de "serviços" é o de: "qualquer atividade fornecida no mercado de consumo, mediante remuneração, inclusive as de natureza bancária, financeira, de crédito e securitária, salvo as decorrentes das relações de caráter trabalhista" ( $\$ 2^{\circ}$ do art. $3^{\circ}$ do CDC). Concluindo que as instituições financeiras efetivamente se sujeitam ao CDC exatamente por haver esta relação de consumo.

\footnotetext{
${ }^{13}$ Art. $3^{\circ}$ Fornecedor é toda pessoa física ou jurídica, pública ou privada, nacional ou estrangeira, bem como os entes despersonalizados, que desenvolvem atividade de produção, montagem, criação, construção, transformação, importação, exportação, distribuição ou comercialização de produtos ou prestação de serviços.

$[\ldots]$

$\S 2^{\circ}$ Serviço é qualquer atividade fornecida no mercado de consumo, mediante remuneração, inclusive as de natureza bancária, financeira, de crédito e securitária, salvo as decorrentes das relações de caráter trabalhista.

${ }^{14}$ Foi declarada a constitucionalidade do art. $3^{\circ}, \S 2^{\circ}$, do CDC e, de conseguinte, concluiu-se pela sujeição de todas as instituições financeiras à aplicabilidade do CDC. ADI 2591 (julgamento em: 07/06/2006). Disponível em: <http://redir.stf.jus.br/paginadorpub/paginador.jsp?docTP=AC\&docID=266855>. Acesso em: 10 mar. 2014 ${ }^{15}$ RESP 298369 (DJU 25/8/2003); RESP 387805 (DJU 9/9/2002); RESP 106888 (DJU 5/8/2002) - RSTJ Vol. 161 P. 226; RESP 175795 (DJU 10/5/1999); RESP 57974 (DJU 29/5/1995) - JTARS Vol. 97 P. 403
} 


\subsection{Os princípios que norteiam o código de defesa do consumidor}

O CDC estabeleceu uma Política Nacional das Relações de Consumo (art. $4^{\text {o }}$, , objetivando o atendimento das necessidades dos consumidores, o respeito à sua dignidade, saúde e segurança, a proteção de seus interesses econômicos, a melhoria da sua qualidade de vida, bem como a transparência e harmonia das relações de consumo, elencando alguns princípios a serem observados e aplicados, dentre eles que o consumidor é a parte vulnerável no mercado de consumo, impôs a ação do Estado nesta proteção.

Esses princípios visavam a transparência e a harmonia das relações de consumo, de acordo com os demais princípios que norteiam o $\mathrm{CDC}$, ao qual nenhum fornecedor poderá se furtar sob pena de configurar tanto a falha na prestação do serviço como o descumprimento da própria Política Nacional das Relações de Consumo, especificamente na racionalização e melhoria dos serviços públicos quando há demora nas filas das instituições financeiras.

\subsection{Dos direitos do consumidor}

O CDC é um conjunto de normas com o objetivo de dar proteção aos direitos do consumidor bem como instruir, regulamentar as relações e as responsabilidades entre o fornecedor (fabricante de produtos ou prestador de serviços) e o consumidor final ao cabo dessa relação, fixando assim alguns parâmetros de conduta, como o cumprimento de prazos e o estabelecimento de penalidades. O CDC, em seu artigo $1^{\circ}$, estabeleceu as normas de proteção e defesa do consumidor, de ordem pública e interesse social, e, estabeleceu no artigo $6^{\mathrm{o} 16}$ os direitos básicos do consumidor.

\footnotetext{
${ }^{16}$ Art. $6^{\circ}$ São direitos básicos do consumidor:

I - a proteção da vida, saúde e segurança contra os riscos provocados por práticas no fornecimento de produtos e serviços considerados perigosos ou nocivos;

II - a educação e divulgação sobre o consumo adequado dos produtos e serviços, asseguradas a liberdade de escolha e a igualdade nas contratações;

III - a informação adequada e clara sobre os diferentes produtos e serviços, com especificação correta de quantidade, características, composição, qualidade, tributos incidentes e preço, bem como sobre os riscos que apresentem;

IV - a proteção contra a publicidade enganosa e abusiva, métodos comerciais coercitivos ou desleais, bem como contra práticas e cláusulas abusivas ou impostas no fornecimento de produtos e serviços;

V - a modificação das cláusulas contratuais que estabeleçam prestações desproporcionais ou sua revisão em razão de fatos supervenientes que as tornem excessivamente onerosas;

VI - a efetiva prevenção e reparação de danos patrimoniais e morais, individuais, coletivos e difusos;
} 
O CDC tem por finalidade proteger o consumidor, promover o equilíbrio contratual, buscando soluções justas e harmônicas. Por isso é que o Código de Defesa do Consumidor apresenta-se marcadamente protecionista, já que as suas normas destinam-se à proteção da parte tida como a mais vulnerável na relação de consumo, ou seja, por óbvio o próprio consumidor (GARCIA, 2208, pp. 36-37).

De acordo com o seu artigo $7^{\circ}$, esses mesmos direitos não excluem outros decorrentes de tratados ou convenções internacionais de que o Brasil seja signatário, da legislação interna ordinária, de regulamentos expedidos pelas autoridades administrativas competentes, bem como dos que derivem de princípios gerais do direito, analogia, costume e equidade.

Dessa forma, essa proteção se faz necessária para evitar desigualdades no âmbito da relação de consumo, e, conforme nos ensina o ex-presidente do Supremo Tribunal de Justiça de Portugal, Ferreira (2013, p. 20):

Têm de existir vários caminhos para a Justiça, conforme as tipologias dos casos concretos, em ordem a dar resposta aos anseios cívicos de quem se considere ofendido. E nesses caminhos - a que podemos chamar jurisdições ou meios jurisdicionais - todos devem respeitar os cidadãos que, de todos, são a razão de ser, e todos devem respeitar-se e harmonizar-se entre si.

E pela busca por caminhos distintos, diante do controle judicial (podendo ainda haver meios extrajudiciais como a mediação ou a conciliação e a arbitragem), o direito de ação é um direito público subjetivo, e pode ser exercido até mesmo contra o Estado, que por sua vez não pode recusar a prestação jurisdicional. Porém, o Estado-juiz não está obrigado a decidir a demanda a favor do autor, devendo aplicar o direito ao caso concreto (BONATTO, 2013, p. 98).

Não resolvido o vício do produto ou da prestação de serviço pelo prestador, deve o consumidor buscar todos os meios para a proteção do seu direito de consumidor, sendo assim, e na busca de caminhos por Justiça, o direito de ação se apresenta, e, conforme Bonatto (2013, p. 98): "Deste modo, verificamos que o direito de ação é um direito cívico e abstrato, ou seja,

VII - o acesso aos órgãos judiciários e administrativos com vistas à prevenção ou reparação de danos patrimoniais e morais, individuais, coletivos ou difusos assegurados à proteção Jurídica, administrativa e técnica aos necessitados;

VIII - a facilitação da defesa de seus direitos, inclusive com a inversão do ônus da prova, a seu favor, no processo civil, quando, a critério do juiz, for verossímil a alegação ou quando for ele hipossuficiente, segundo as regras ordinárias de experiências;

IX - (Vetado);

$\mathrm{X}$ - a adequada e eficaz prestação dos serviços públicos em geral. 
é um direito subjetivo à sentença judicial, de acolhimento ou de rejeição da pretensão, desde que se encontrem preenchidas as condições da ação."

\subsection{A relação entre o consumidor e fornecedor}

Para compreender essa relação de consumo foi necessário estabelecer conceitos aos termos consumidor, fornecedor, serviços e produto, para o quê o $\mathrm{CDC}^{17}$ assim o fez. Em complemento, o parágrafo único do art. $2^{\circ}$ esclarece que se equiparam aos consumidores todas as pessoas determináveis ou não, expostas às práticas nele previstas.

Além disso, existe também a Política Nacional de Relações de Consumo que objetiva o atendimento das necessidades dos consumidores bem como o respeito à sua dignidade, a saúde e segurança, a proteção de seus interesses econômicos, melhoria da sua qualidade de vida, bem como a transparência e harmonia dessas mesmas relações, com os instrumentos que o artigo $5^{\circ}$ do CDC lhe forneceu, sempre com vistas à melhor e efetiva proteção de todo consumidor.

\subsection{Da qualidade dos serviços bancários prestados}

Os produtos e serviços colocados no mercado de consumo não acarretarão riscos à saúde ou segurança dos consumidores, exceto os considerados normais e previsíveis em decorrência de sua natureza e fruição, obrigando-se os fornecedores, em qualquer hipótese, a dar as informações necessárias e adequadas a seu respeito conforme descrito no artigo $8^{\circ}$ do CDC. Por sua vez, o fornecedor de serviços responde independentemente da existência da culpa, assim, sua responsabilidade é objetiva e a ocorrência de sua culpa é irrelevante, sendo tal verificação desnecessária, pois há interferência na responsabilização civil, e para a

17 Art. $2^{\circ}$ Consumidor é toda pessoa física ou jurídica que adquire ou utiliza produto ou serviço como destinatário final.

Parágrafo único. Equipara-se o consumidor a coletividade de pessoas, ainda que indetermináveis, que haja intervindo nas relações de consumo.

Art. $3^{\circ}$ Fornecedor é toda pessoa física ou jurídica, pública ou privada, nacional ou estrangeira, bem como os entes despersonalizados, que desenvolvem atividade de produção, montagem, criação, construção, transformação, importação, exportação, distribuição ou comercialização de produtos ou prestação de serviços. $\S 1^{\circ}$ Produto é qualquer bem, móvel ou imóvel, material ou imaterial.

$\S 2^{\circ}$ Serviço é qualquer atividade fornecida no mercado de consumo, mediante remuneração, inclusive as de natureza bancária, financeira, de crédito e securitária, salvo as decorrentes das relações de caráter trabalhista. 
reparação de danos, ao particular, basta a demonstração do evento danoso, do nexo causal, do dano a ser indenizado e sua extensão (ALMEIDA, 2008, p. 88).

É um vício da qualidade do serviço bancário não atender as normas regulamentares de prestabilidade, no caso, as leis municipais e estaduais fixadoras do tempo máximo de espera por atendimento em uma fila, sendo assim, o prestador de serviço responde objetivamente pelos danos daí advindos ( $\$ 2^{\circ}$ do artigo 20, do CDC). Nesse caso, em se tratando também de órgãos públicos, empresas, concessionárias, permissionárias, ou de qualquer outra forma de empreendimento, são obrigados a fornecer serviços adequados, eficientes, seguros e, quanto aos essenciais contínuos. E no caso de descumprimento, total ou parcial, dessas obrigações, serão as pessoas jurídicas compelidas a cumpri-las e a reparar os danos causados, objetivamente, na forma prevista no CDC.

A jurisprudência pátria até já caminhou para o entendimento aqui defendido, de lesão à dignidade da pessoa humana quando uma instituição financeira não cumpre o tempo regulamentar de espera em uma fila, tanto que o Tribunal de Justiça do Estado de Sergipe $\left(\mathrm{TJSE}^{18}\right)$ já sumulou este entendimento: "Súmula $\mathrm{n}^{\circ}$ 4. A espera em fila de agência bancária, por tempo excessivo, caracteriza falha na prestação do serviço e poderá ensejar reparação por danos morais. (DJ 30.11.2011).”.

Com a evolução jurisprudencial, com vistas ao princípio da dignidade da pessoa humana, cujo papel da doutrina é importante, em sede de reparação de danos, o dano moral é evidente e incontestável, decorrendo in re ipsa, ou seja, quando uma pessoa passa horas em instituições financeiras, em uma ou mais filas, suplicando por um atendimento digno, sofre dano moral por causa das modificações negativas à sua pessoa em seu estado de bem-estar, em seu íntimo, o que prescinde de comprovação, bastando a demonstração do ato ilícito e do nexo causal, os quais restaram evidenciados na hipótese, até porque contrariam as normas regulamentares deste serviço bancário, praticando um ato ilícito, que se enquadra nos artigos $186^{19}, 187$ e 927 do Código Civil Brasileiro.

\footnotetext{
18 Disponível em: < http://www.tjse.jus.br/portal/arquivos/documentos/publicacoes/sumulas/sumula-004-IUJ002-2011.pdf>. Acesso em: 27 jun. 2014.

${ }^{19}$ DOS ATOS ILÍCITOS

Art. 186. Aquele que, por ação ou omissão voluntária, negligência ou imprudência, violar direito e causar dano a outrem, ainda que exclusivamente moral, comete ato ilícito.

Art. 187. Também comete ato ilícito o titular de um direito que, ao exercê-lo, excede manifestamente os limites impostos pelo seu fim econômico ou social, pela boa-fé ou pelos bons costumes.

Art. 927. Aquele que, por ato ilícito (arts. 186 e 187), causar dano a outrem, fica obrigado a repará-lo.
} 
E o dano praticado pelas instituições financeiras pode também ser de ordem patrimonial, quando advém de ato que lesiona o patrimônio material de uma pessoa que, por exemplo, perde o horário para o pagamento de uma obrigação em outro banco e é penalizado com os ônus de sua mora (juros, multa e correções).

\section{A ATUAÇÃO DAS INSTITUIÇÕES FINANCEIRAS}

$\mathrm{Na}$ crescente evolução consumista, faz-se necessária cada vez mais a utilização dos serviços oferecidos pelas instituições financeiras, mas, infelizmente, essa relação de “dependência" não é tão simples e tão cômoda assim. Ocorre que as instituições financeiras estão cada vez mais sólidas e acumulando lucros exorbitantes num mercado econômico financeiro extremamente promissor em face da diferença - spread bancário - entre os juros que pagam aos clientes/aplicadores e os que cobram nas suas operações ${ }^{20}$.

No caso específico deste artigo, nota-se o descaso dessas instituições quando o assunto é $\mathrm{o}$ atendimento ao cliente dentro de suas agências bancárias, isto porque o tempo de espera em uma fila para qualquer tipo de movimentação não é menor que $1 \mathrm{~h}$ em dias normais. $\mathrm{O}$ descaso aumenta, quando o cliente se dirige às agências em dias de maior movimento, como o $5^{\circ}$ dia útil ou em caso de feriado prolongado. Para agravar a situação, o sistema virtual não admite toda e qualquer movimentação bancária, sem contar que muitos preferem ir às agências para cumprir seus compromissos.

O que se percebe claramente é que o número de empregados no setor bancário brasileiro diminui enquanto o faturamento cresceu, conforme afirma ${ }^{21}$ o presidente da Confederação Nacional dos Trabalhadores do Ramo Financeiro (CONTRAF), já que os 508 mil empregos no setor em 2012 representam apenas 69,4\% do total que o setor tinha em 1990 (732 mil bancários), portanto, o número de bancários nas agências bancárias vem diminuindo enquanto as instituições financeiras registraram lucro líquido acima de R\$ 5 bilhões em $2013^{22}$. Mas

Parágrafo único. Haverá obrigação de reparar o dano, independentemente de culpa, nos casos especificados em lei, ou quando a atividade normalmente desenvolvida pelo autor do dano implicar, por sua natureza, risco para os direitos de outrem.

${ }^{20}$ Disponível em: <http://veja.abril.com.br/blog/acervo-digital/economia/em-dia-por-que-os-bancos-tem-lucrostao-grandes-no-brasil/>. Acesso em: 12 mar. 2014

21 Disponível em: <http://memoria.ebc.com.br/agenciabrasil/noticia/2012-07-22/dieese-mesmo-crescendo-nosultimos-dez-anos-emprego-no-setor-bancario-e-70-do-total-ha-duas-decadas>. Acesso em: 12 mar. 2014

22 Disponível em: <http://www.feebpr.org.br/lucroban.htm>. Acesso em: 12 mar. 2014 
diante da retração do nível de emprego do setor bancário, portanto, daqueles que lidam diretamente com os clientes, o dado inverso é o do crescimento populacional, que segundo a informação demográfica do IBGE (BRASIL, 2008, pp. 19 e 28), a população que em 1991 era de mais de 146 milhões brasileiros, para 2014 a projeção é de que atinja os 200 milhões.

O consumidor tem o direito à proteção contra essa prática abusiva, mas os fornecedores, e neste caso são as instituições financeiras, vêm sendo recordistas na violação desse direito, expondo os consumidores a situações desumanas, fazendo-o esperar por várias horas em filas intermináveis, sem disponibilizar assentos em número suficiente, sem fornecer água e sanitários, o que é humilhante, cansativo e estressante, gerando angústias e ansiedades, porque também impede o consumidor de cumprir outros compromissos, podendo, inclusive, gerar-lhe danos materiais.

É inaceitável que clientes aguardem mais de uma hora, estando de pé ou não, sofrendo total desconforto, sem sequer alguma previsão de quando será atendido. Nota-se claramente o investimento dentro das instituições financeiras no atendimento virtual, e até mesmo na extensão dos chamados correspondentes bancários (lotéricas, supermercados, drogarias), porém a falha do serviço no atendimento físico é um defeito e um flagrante abuso na prestação destes serviços.

O Poder Judiciário tem sido utilizado pela população para punir e responsabilizar, material e moralmente, essa demora injustificada nas filas de agências bancárias, sendo motivo de pagamento de indenizações para aqueles que infringirem a legislação que estipula um determinado tempo para que o atendimento bancário seja efetuado. Vários Estados já possuem legislação a respeito deste tema, e, especificamente em Minas Gerais, a Lei Estadual $\mathrm{n}^{\mathrm{o}} 14.235^{23}$, de 26/4/2002, disciplina o atendimento aos consumidores por parte das instituições financeiras do Estado, norma que se tornou conhecida como Lei dos 15 minutos, estabelecendo além de tempo máximo para o cliente bancário ser atendido (art. $1^{\mathbf{0 2 4}}$ ), normas para conforto, saúde e higiene dos consumidores (art. $4^{\circ}$ ).

<http://www.almg.gov.br/consulte/legislacao/completa/completa.html?tipo=LEI\&num=14235\&comp=\&ano=20 02>. Acesso em: 11 mar. 2014.

${ }^{24}$ Art. $1^{\circ}$ - Fica o estabelecimento bancário obrigado a atender o cliente no prazo de quinze minutos contados do momento em que ele entrar na fila de atendimento.

$[\ldots]$

Art. $4^{\circ}$ - O estabelecimento bancário é obrigado a instalar banheiro e bebedouro para os clientes. 
De lege ferenda, o Projeto de Lei n. 991/2011 da Assembléia Legislativa de Minas Gerais (ALMG), na forma do seu Substitutivo n. $1^{25}$, buscou evoluir a legislação estadual já existente, tendo constatado que a delimitação do tempo de espera para atendimento por parte das instituições financeiras tornou-se lei em diversos outros Estados e também em centenas de Municípios do País. Em razão do que, visa melhorar o atendimento dos clientes com a distribuição de senhas com hora da entrada do consumidor na instituição financeira e a hora do atendimento no caixa, facilitando a físcalização pelos órgãos de defesa do consumidor, onde esta senha: "torna-se instrumento hábil para que os órgãos de proteção e defesa do consumidor possam obter uma prova documental e penalizar a instituição financeira que descumprir a lei no que tange ao tempo de espera para atendimento.”.

Neste mesmo sentido, uma onda de leis municipais passou a ser editadas para regulamentarem o tempo de espera em fila de bancos, e daí algumas instituições financeiras foram em busca do mesmo Poder Judiciário para o questionamento quanto à competência do Município em legislar a respeito do tema. De acordo com o STF, no julgamento do Recurso Extraordinário 610.221/SC ${ }^{26}$ a respeito da matéria, decidiu-se que o Município tem sim competência para legislar a respeito do tempo de espera de clientes na fila de banco. E nesse mesmo foi decidido pela $1^{\mathrm{a}}$ Turma do STF quando julgou o Recurso Extraordinário n.

<http://www.almg.gov.br/atividade_parlamentar/tramitacao_projetos/documento.html?a=2011\&n=991\&t=PL\&d $\mathrm{oc}=1>$. Acesso em: 11 mar. 2014.

${ }^{26}$ RECURSO EXTRAORDINÁRIO 610.221 SANTA CATARINA RELATORA: MIN. ELLEN GRACIE RECTE. (S) : CAIXA ECONÔMICA FEDERAL - CEF ADV.(A/S) :KARINE VOLPATO GALVANI E OUTRO(A/S) RECDO.(A/S) :MUNICÍPIO DE CHAPECÓ PROC.(A/S)(ES): PROCURADOR-GERAL DO MUNICÍPIO DE CHAPECÓ 1. A hipótese dos autos versa sobre a validade de lei municipal que dispõe sobre o tempo de espera de clientes em filas de bancos. O acórdão entendeu pela constitucionalidade da Lei 3.975/99 do Município de Chapecó. 2. Este Tribunal, no julgamento do RE 610.221, de minha relatoria, reconheceu a existência da repercussão geral da matéria para que os efeitos do art. 543-B do CPC possam ser aplicados. Esta Corte firmou entendimento no sentido de que os municípios têm competência para legislar sobre assuntos de interesse local. Nesse sentido: AC 1.124-MC, rel. Min. Marco Aurélio, $1^{\mathrm{a}}$ Turma, DJ 04.08.2006; AI 491.420AgR, rel. Min. Cezar Peluso, $1^{a}$ Turma, DJ 24.03.2006; AI 709.974-AgR, rel. Min. Cármen Lucia, $1^{a}$ Turma, DJe 26.11.2009; RE 432.789, rel. Min. Eros Grau, ${ }^{\text {a }}$ Turma, DJ 07.10.2005; AI 347.717-AgR, rel. Min. Celso de Mello, $2^{\mathrm{a}}$ Turma, DJ 05.08.2005; AI 747.245-AgR, rel. Min. Eros Grau, $2^{\mathrm{a}}$ Turma, DJe 06.08.2009; AI 574.296, rel. Min. Gilmar Mendes, $2^{\mathrm{a}}$ Turma, DJ 16.06.2006; RE 559.650, rel. Min. Carlos Britto, DJe 02.12.2009. O acórdão recorrido não divergiu desse entendimento. 3. Ante o exposto, nego seguimento ao recurso extraordinário. Com base nessa decisão, julgo prejudicados os pedidos de ingresso como amici curiae formulado pela Câmara Municipal do Rio de Janeiro (Petição STF 31.299/2010 - fls. 133-135) e pela Federação Brasileira de Bancos - FEBRABAN (Petição STF 40.545/2010 - fls. 155-163). Publique-se. Brasília, 27 de agosto de 2010.Ministra Ellen Gracie Relatora. Disponível em: <http://www.stf.jus.br/portal/jurisprudencia/listarJurisprudencia.asp?s1=\%28RE\%24\%2ESCLA\%2E+E+610221 \%2ENUME\%2E\%29\&base=baseMonocraticas\&url=http://tinyurl.com/dygdckw $>$. Acesso em: 03 mar. 2014. 
$432789 / \mathrm{SC}^{27}$.

As referidas legislações municipais, com base justamente nesse interesse loção, na sua maioria limitam um determinado tempo para o atendimento, prevendo a responsabilização (advertência, multa, cassação de alvará de funcionamento) em caso de exceder esse limite, levando a uma nova discussão se haveria o cabimento ou não dos danos morais (REsp 1218497/MT ${ }^{28}$ julgado pela $3^{\text {a }}$ Turma do STJ em 11/09/2012).

Mas, quando do julgamento do REsp 608918/RS ${ }^{29}$, em 21/6/2004, o Ministro José Delgado, da $1^{\text {a }}$ Turma do STJ, já deixava claro que naquele Tribunal da Cidadania:

Deve ser banida da cultura nacional a idéia de que ser mal atendido faz parte dos aborrecimentos triviais do cidadão comum, principalmente quando tal comportamento provém das entidades administrativas. O cidadão não pode ser compelido a suportar as conseqüências da má organização, abuso e falta de eficiência daqueles que devem, com toda boa vontade, solicitude e cortesia, atender ao público.

27 EMENTA: RECURSO EXTRAORDINÁRIO. CONSTITUCIONAL. CONSUMIDOR. INSTITUIÇÃO BANCÁRIA. ATENDIMENTO AO PÚBLICO. FILA. TEMPO DE ESPERA. LEI MUNICIPAL. NORMA DE INTERESSE LOCAL. LEGITIMIDADE. Lei Municipal n. 4.188/01. Banco. Atendimento ao público e tempo máximo de espera na fila. Matéria que não se confunde com a atinente às atividades-fim das instituições bancárias. Matéria de interesse local e de proteção ao consumidor. Competência legislativa do Município. Recurso extraordinário conhecido e provido. Decisão: A Turma conheceu do recurso extraordinário e lhe deu provimento, nos termos do voto do Relator. Unânime. Falou pelo recorrido a Dra. Magda Montenegro. $1^{a}$. 14.06.2005. Disponível em:

http://www.stf.jus.br/portal/jurisprudencia/listarJurisprudencia.asp?s1=\%28RE\%24\%2ESCLA\%2E+E+432789 $\% 2 \mathrm{ENUME} \% 2 \mathrm{E} \% 29+\mathrm{OU}+\% 28 \mathrm{RE} \% 2 \mathrm{EACMS} \% 2 \mathrm{E}+\mathrm{ADJ} 2+432789 \% 2 \mathrm{EACMS} \% 2 \mathrm{E} \% 29 \&$ base=baseAcordaos \&url=http://tinyurl.com/b2m7qdq>. Acesso em: 03 mar. 2014.

${ }^{28}$ AÇÃO DE INDENIZAÇÃO. ESPERA EM FILA DE BANCO POR MAIS DE UMA HORA. TEMPO SUPERIOR AO FIXADO POR LEGISLAÇÃO LOCAL. INSUFICIÊNCIA DA SÓ INVOCAÇÃO LEGISLATIVA ALUDIDA. PADECIMENTO MORAL, CONTUDO, EXPRESSAMENTE ASSINALADO PELA SENTENÇA E PELO ACÓRDÃO, CONSTITUINDO FUNDAMENTO FÁTICO INALTERÁVEL POR ESTA CORTE (SÚMULA 7/STJ). INDENIZAÇÃO DE R\$ 3.000,00, CORRIGIDA DESDE A DATA DO ATO DANOSO (SÚMULA 54/STJ). 1. - A espera por atendimento em fila de banco quando excessiva ou associada a outros constrangimentos, e reconhecida faticamente como provocadora de sofrimento moral, enseja condenação por dano moral. 2. - A só invocação de legislação municipal ou estadual que estabelece tempo máximo de espera em fila de banco não é suficiente para desejar o direito à indenização, pois dirige a sanções administrativas, que podem ser provocadas pelo usuário. 3. - Reconhecidas, pela sentença e pelo Acórdão, as circunstâncias fáticas do padecimento moral, prevalece o julgamento da origem (Súmula 7/STJ). 4. - Mantém-se, por razoável, o valor de 3.000,00, para desestímulo à conduta, corrigido monetariamente desde a data do evento danoso (Súmula 54/STJ), ante as forças econômicas do banco responsável e, inclusive, para desestímulo à recorribilidade, de menor monta, ante aludidas forças econômicas. 5. - Recurso Especial improvido. Disponível em:

<http://www.stj.jus.br/SCON/jurisprudencia/toc.jsp?tipo_visualizacao=null\&processo=1218497\&b=ACOR\&the saurus=JURIDICO $>$. Acesso em: 4 mar. 2014. 29 
Portanto, nem tanto somente pela existência de legislação reguladora, mas, principalmente, pela espera excessiva ou outros constrangimentos, pode haver a responsabilização dessas instituições financeiras pelos danos morais causados pelo sofrimento experimentado pelo cliente, inclusive por eventuais danos materiais, também. Mas, ao que parece, essas instituições não se preocuparam com estas decisões aqui e acolá, até porque parte dos seus altos lucros já se destina ao pagamento dessas indenizações, as quais, em virtude da baixa demanda judiciária pelos consumidores dos serviços bancários, mostram-se ínfimas, exatamente porque continua custando muito mais barato descumprir a legislação e afrontar a dignidade das pessoas.

\section{CONSIDERAÇÕES FINAIS}

Com o desenvolvimento tecnológico e digital, as instituições financeiras aderiram aos sistemas informatizados e meios telemáticos, com investimentos em novos softwares desenvolvidos, única e exclusivamente, para o atendimento virtual, com o objetivo de expandir esse mesmo atendimento, virtualmente, para tentar solucionar a demanda dentro das agências bancárias.

Entretanto, mesmo com esse tipo de serviço, em uma rede invisível, dentro dos padrões de segurança garantidos pelas instituições financeiras, muitos clientes não aderiram a tal prática, ou então, ainda não dispõem de tal meio para determinado serviço bancário, quando os clientes são obrigados a se dirigirem às agências para um atendimento personalizado ou mais seguro.

A partir da constatação do grande investimento por parte dessas mesmas instituições, objetivando um melhor e mais completo atendimento virtual, tal atendimento passou a ser sua prioridade. Porém, e com relação ao atendimento físico dentro das próprias agências, não se fez o investimento com o mesmo cuidado ou com o mesmo zelo para com seus clientes, que ainda buscam ou são obrigados a um atendimento pessoal (cliente físico) para a concretização do seu serviço bancário no dia-a-dia, pelos mais diversos motivos (analfabetos, sem conhecimentos de informática, os chamados “excluídos da era digital” etc.).

E neste caso, os clientes são consumidores porque na relação existente entre instituição financeira (sujeito ativo e prestador de serviço), esta não se exime dos critérios e submissões 
que o nosso ordenamento jurídico lhes impõe com o objetivo de resguardar os direitos da outra parte, ou seja, do consumidor, portanto, do sujeito passivo dessa relação consumerista.

$\mathrm{O}$ consumidor tem direito a um serviço de qualidade, que seja eficaz, adequado às suas necessidades e conforme as normas regulamentares. O fornecedor por sua vez, no caso, as instituições financeiras, deverão proporcionar este serviço, e caso não consigam êxito, caracterizados estão um vício na qualidade do serviço prestado bem como uma prática abusiva, consequentemente, deverão ser responsabilizadas administrativamente, e, ainda, judicialmente, condenadas provavelmente em ações que demandam pedidos de indenizações de danos morais, sem prejuízo, inclusive, de causarem também danos materiais.

Aguardar mais de uma hora numa fila de banco para conseguir findar qualquer serviço é algo degradante, desonroso, insultuoso, ofensivo à dignidade da pessoa humana, chegando a ser vergonhoso por conta da ausência de estrutura física e de pessoal para atender a demanda de serviços. Percebe-se que o investimento dessas instituições financeiras na quantidade de funcionários dentro de suas agências é algo constrangedor. É notória a despreocupação com relação à prestação de um serviço/atendimento satisfatório aos clientes e consumidores de seus serviços, mesmo havendo legislação que estabeleça limites temporais a este atendimento.

Concluímos que a demora injustificada na fila de banco nada mais é que uma prática abusiva que desrespeita normas regulamentadoras causando prejuízos (morais e materiais) notórios aos clientes/consumidores, principalmente no sentido emocional, pelo descaso na qualidade do serviço prestado, bem como avilta um dos princípios mais importantes do nosso ordenamento jurídico, violando a dignidade da pessoa humana.

\section{REFERÊNCIAS}

ALMEIDA, João Batista de. A proteção jurídica do consumidor. 6. ed. rev., atual. e ampl. São Paulo: Saraiva, 2008.

ARAÚJO, Luiz Alberto David; NUNES JUNIOR, Vidal Serrano. Curso de direito constitucional. 16. ed. São Paulo: Editora Verbetem, 2012.

ASCENSÃO, José de Oliveira. O direito. Introdução e teoria geral. 13. ed. reimp. Coimbra: Edições Almedina, 2005. 
ANDRADE, André Gustavo Correa de. O princípio fundamental da dignidade humana e sua concretização judicial. Texto disponibilizado no Banco do Conhecimento do Tribunal de Justiça do Rio de Janeiro em 18 de agosto de 2008. Disponível em: <http://www.tjrj.jus.br/institucional/dir_gerais/dgcon/pdf/artigos/direi_const/o_principio_fun damental_da_dignidade_humana_e_sua_concretizacao_judicial.pdf $>$. Acesso em: 5 mar. 2014.

BARROSO, Luís Roberto. A dignidade da pessoa humana no direito constitucional contemporâneo: a construção de um conceito jurídico à luz da jurisprudência mundial. 2. reimp. Belo Horizonte: Fórum, 2013.

BITTAR FILHO, Carlos Alberto. Direitos do consumidor: dano moral e cláusulas abusivas. 2. ed. São Paulo: IOB Thomson, 2007.

BONATTO, Claudio. O controle das cláusulas abusivas nas relações contratuais de consumo. Revista Luso-Brasileira de Direito do Consumo, Curitiba, v. III, n. 10, p. 87-110, jun. 2013.

BRASIL, Ministério do Planejamento, Orçamento e Gestão. Instituto Brasileiro de Geografia e Estatística - IBGE. Diretoria de Pesquisas. Coordenação de População e Indicadores Sociais. Estudos e Pesquisas. Informação Demográfica e Socioeconômica número 24. Projeção da população do Brasil por sexo e idade 1980-2050. Rio de Janeiro, 2008. Disponível em: <http://www.ibge.gov.br/home/estatistica/populacao/projecao_da_populacao/2008/projecao.p df >. Acesso em: 13 mar. 2014.

CANOTILHO, J. J. Gomes. Direito constitucional e a teoria da constituição. 7. ed. São Paulo: Almedina, 2003.

CÓDIGO BRASILEIRO DE DEFESA DO CONSUMIDOR. Comentado pelos autores do anteprojeto / Ada Pellegrini Grinover... [et al.]. 9. ed. Rio de Janeiro: Forense Universitária, 2007.

COLlOSSAL, Jane de Araújo. Responsabilidade civil no código de defesa do consumidor. São Paulo: Dicionário Jurídico, 2007.

FERREIRA, Jaime Octávio Cardona. Julgados de paz e justiça. Revista Luso-Brasileira de Direito do Consumo, Curitiba, v. III, n. 10, p. 13-32, jun. 2013. 
GARCIA, Leonardo de Medeiros. Direito do consumidor. 4. ed. Niterói, RJ: Ímpetos, 2008.

HESSE, Konrad. A força normativa da constituição (die normative Kraft der Verfassung). Trad. Gilmar Ferreira Mendes. Porto Alegre: Sérgio Augusto Fabris Editor, 1991.

MELLO, Celso Antônio Bandeira. Elementos de direito administrativo. São Paulo: Revista dos Tribunais, 1981.

NUNES, Luís Antônio Rizzatto. Curso de direito do consumidor: com exercícios. 4. ed. São Paulo: Saraiva, 2009.

OLIVEIRA, José Carlos de. Código de defesa do consumidor: doutrina, jurisprudência e legislação complementar. 3. ed. São Paulo: Lemos e Cruz, 2002.

REALE, Miguel. Lições preliminares de direito. 19. ed. São Paulo: Saraiva, 1991.

ROTHENBURG, Walter Claudius. Princípios constitucionais. 2. ed. Porto Alegre: Sérgio Augusto Fabris Editor, 2003.

SARLET, Ingo Wolfgang. Dignidade da pessoa humana e direitos fundamentais na constituição federal de 1988. Porto Alegre: Livraria do Advogado, 2001.

SILVA, José Afonso da. Curso de direito constitucional positivo. 32. ed. São Paulo: Malheiros, 2009.

UNESCO, Declaração universal dos direitos humanos. Disponível em: <http://unesdoc.unesco.org/images/0013/001394/139423por.pdf>. Acesso em: 3 fev. 2014.

Submissão: 14/03/2014 Aceito para Publicação: 01/07/2014 